\title{
Electrical conductivity structures estimated by thin sheet inversion, with special attention to the Beppu-Shimabara graben in central Kyushu, Japan
}

\author{
Shun Handa \\ Faculty of Agricultural Science, Saga University, Honjo 1, Saga 840-8502, Japan
}

(Received February 3, 2005; Revised April 25, 2005; Accepted May 11, 2005)

\begin{abstract}
It is proposed that the Beppu-Shimabara graben (BSG), characterized by the continuous negative Bouguer anomaly, runs NE to SW in central Kyushu. In order to clarify the BSG, the shallow electrical conductivity structure in central Kyushu is obtained by thin sheet modeling using the inversion of a conjugate gradient relaxation method and also using the forward method. The data used are the single-site transfer functions at 75 sites for the periods of 77, 97 and $122 \mathrm{sec}$. The inverted model indicates three highly conductive areas: these are the Saga-Chikugo plain covered with thick alluvium and the eastern and the western parts of central Kyushu including the BSG. Both end zones of this BSG are highly conductive in our model, which is closely related to conductive layers shallower than about $1 \mathrm{~km}$. In contrast, the central part of the BSG is rather highly resistive. The BSG, thus, is not revealed as a continuous high-conductive belt and seems to be separated into three parts; the eastern and the western high-conductive zones and the central resistive area in our geoelectrical model of the shallow crust.
\end{abstract}

Key words: Electrical conductivity, Beppu-Shimabara graben, thin sheet model, inversion, GDS.

\section{Introduction}

Central Kyushu is a tectonically active region; four volcanoes-Tsurumi, Kuju, Aso, and Unzen (Fig. 1)—are active now and earthquakes occur frequently in the shallow crust. In this region, the NS extensional strain field is dominant, in contrast to the EW compressional field in other areas of Japan. As a result, the active fault systems of a normal fault-type are well developed, especially in the Beppu area and the Shimabara Peninsula where the grabens are formed. Matsumoto (1979) pointed out that erupted volcanic rocks covering wide areas are closely related to the formation of these basinal features. He then proposed the Beppu-Shimabara graben (BSG) running through central Kyushu in a NE-SW direction as shown in Fig. 1. Analyzing the focal mechanism of shallow earthquakes, Eguchi and Uyeda (1983) suggested that this graben is a rift zone in the northeastern extension of the Okinawa Trough.

Some geological and petrologic results, however, do not seem to support a close relationship between the BSG and the formation of volcanoes. In central-eastern Kyushu, eruptions ejecting a large quantity of volcanic rocks took place between 6 and 1 Ma in a triangular region surrounded by the tectonic lines of Matsuyama-Imari (MIL) and OitaKumamoto (OKL) and the southern extension (HHL) of the Kokura-Tagawa fault zone (Kamata, 1989). Kamata (1989) pointed out that this area, which he called the Hohi volcanic zone, is a volcano-tectonic depression where the formation of the zone and eruptions occur simultaneously, and thus the rifting of the Okinawa Trough hardly supports this con-

Copy right(C) The Society of Geomagnetism and Earth, Planetary and Space Sciences (SGEPSS); The Seismological Society of Japan; The Volcanological Society of Japan; The Geodetic Society of Japan; The Japanese Society for Planetary Sciences; TERRAPUB. jecture. Moreover, Unzen Volcano in the Shimabara graben is a different type of volcano from the other three active volcanoes in volcanological and structural history (Kamata, 1989) as well as in the chemical composition of its magma source (Nakada and Kamata, 1991).

Although the BSG is one of the most important themes in the tectonics of Kyushu, as mentioned above, the structure is not well understood, because central Kyushu is commonly covered with volcanic formations and basement rocks appear only in narrow areas, as shown in Fig. 1. In order to investigate the electrical structures beneath central Kyushu, we have conducted geomagnetic depth sounding (GDS) studies since 1983 (Handa et al., 1992). The electrical conductivity models (Handa et al., 1992; Shimoizumi et al., 1997) based on these data, indicate the following results: the in-phase induction arrows, i.e., Parkinson's arrows (Parkinson, 1962), for periods of longer than $5 \mathrm{~min}$ tend to point towards the west or the southwest in central Kyushu. This direction is partly explained by the land-sea configuration, but to fully account for it, there must be a high-conductive layer in the upper mantle under the East China Sea.

In the previous study (Handa et al., 1992), modeling was performed by focusing on the deep structure of the lower crust and the upper mantle, as the observation sites used were insufficient to discuss the detailed structure of the shallow crust. Since 1989, we have conducted new GDS observations at 55 sites. These GDS data at the sites that are densely and widely distributed permit the construction of the electrical conductivity model in the entire region of the BSG. Thus, by using the thin sheet modeling technique, we will discuss the shallow resistivity structure, mainly of the BSG in central Kyushu, which is expected to be 


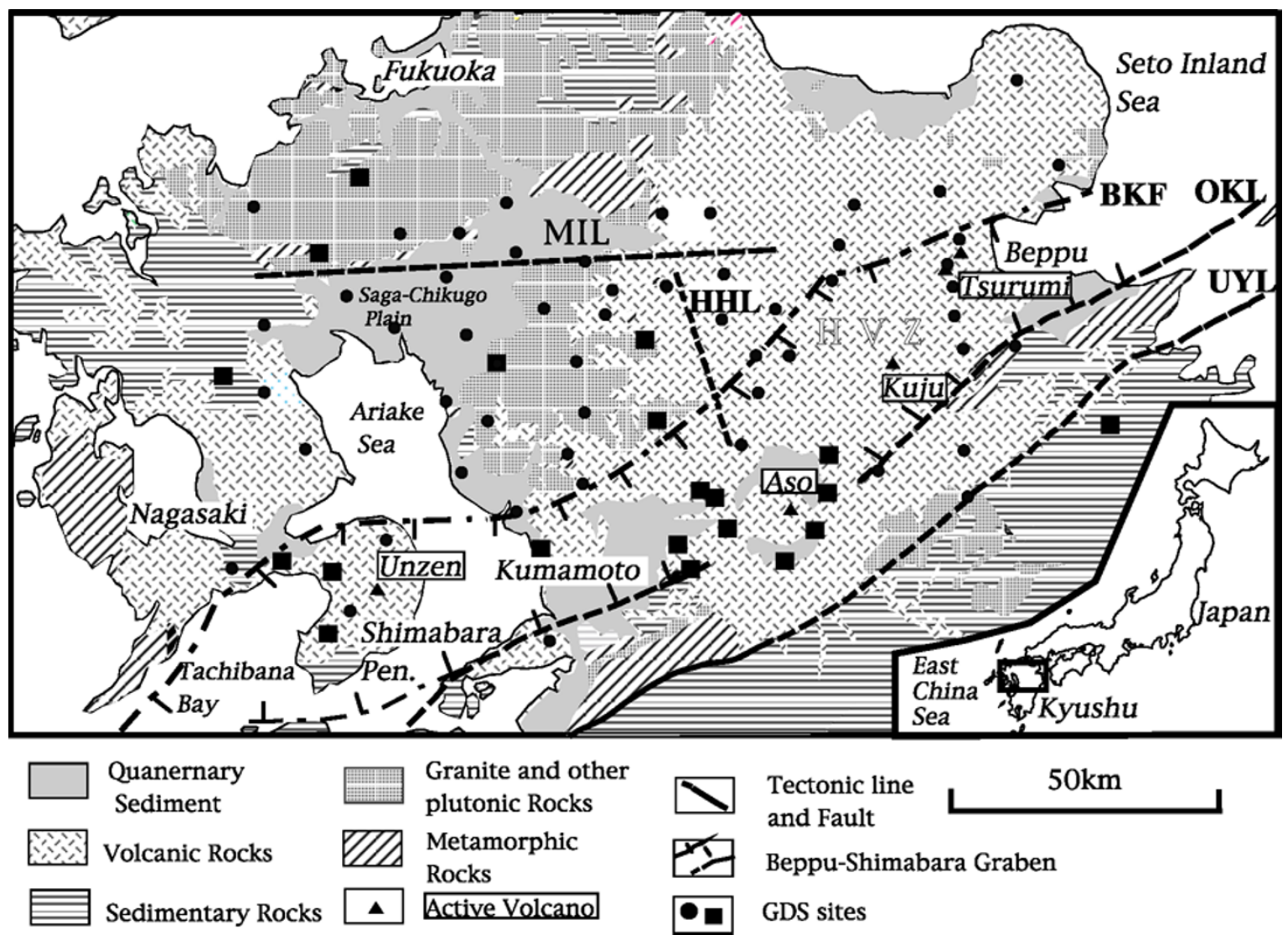

Fig. 1. Survey area with geological map compiled from Editorial Committee of Kyushu, Part 9 of Regional Geology of Japan (1992). GDS sites are indicated by circles and squares. BKF: Beppu-Kita fault, HHL: Hita-Hakuso tectonic line, HVZ: Hohi volcanic zone, MIL: Matsuyama-Imari tectonic line, OKL: Oita-Kumamoto tectonic line, UYL: Usuki-Yatsushiro tectonic line.

'continuous' and rather conductive structures than the other areas.

\section{Induction Arrows}

Assuming that the $z$-component of the external field is small enough, three components of magnetic fields $(H)$ are related as $H z=A H x+B H y$ where the suffixes $x, y$ and $z$ represent the north, east, and downward components, respectively. All the quantities are frequency dependant complex numbers. This relation implies that the vertical component of the magnetic field is caused by current induced in the earth. Thus, the parameters $A$ and $B$, called the 'transfer functions', represent the electromagnetic responses of the Earth. Using the transfer function, the NS and EW components of the in-phase and the quadrature-phase arrows are denoted as $(-A u,-B u)$ and $(-A v,-B v)$ where the subscripts $u$ and $v$ represent the real and imaginary parts, respectively. As the negative orientation of the inphase arrow was chosen in accordance with the orientation of Parkinson's arrows, the in-phase arrow tends to point towards anomalous currents in the conductor.

The locations of the 75 GDS sites used in this study are shown by solid circles and squares in Fig. 1 with the geological map. Their in- and quadrature-phase arrows at the periods of 97 and $487 \mathrm{sec}$ are shown in Fig. 2. All the vectors are estimated from the geomagnetic variation data that were observed in the night-time during 0030 and 0430 JST to avoid cultural noises, with a sampling interval of 1 and $10 \mathrm{sec}$. The vectors at the sites indicated by closed circles in Fig. 1 are estimated using the robust method (Egbert and Booker, 1986). As the magnetic variation data at the 20 sites presented in Handa et al. (1992), which are indicated by closed squares in Fig. 1, were recorded on the old type magnetic tape, these signals, unfortunately, cannot be read now to re-calculate the transfer function using the robust method. In Fig. 2, plus or minus one standard deviation of azimuthal uncertainty in each arrow is marked by the short lines drawn from the foot of the arrow. Figure 3 shows the estimation errors of amplitudes for four sites where the robust method was applied. The application of the robust method reduces the estimation error especially of the quadrature-phase arrows but the errors are still large for periods shorter than about $100 \mathrm{sec}$.

Figure 2 shows that almost all the in-phase arrows at 487 sec point WSW or SW. This tendency accords well with the previous result (Handa et al., 1992) that the arrows for long periods are controlled mainly by the regional current that intensely flows into the sea. In contrast, the in-phase arrows at $97 \mathrm{sec}$ are highly scattered, which implies local complex conductivity structures in the shallow part of the crust: According to the fact that the in-phase arrows at both sides of the region where high-conductivity bodies lie underneath, point toward each other and are relatively small near the center, three shaded regions of high-conductivity (I, $\mathrm{N}$ and $\mathrm{S}$ ) are listed in Fig. 2.

The dependence of the in-phase amplitudes on period in 

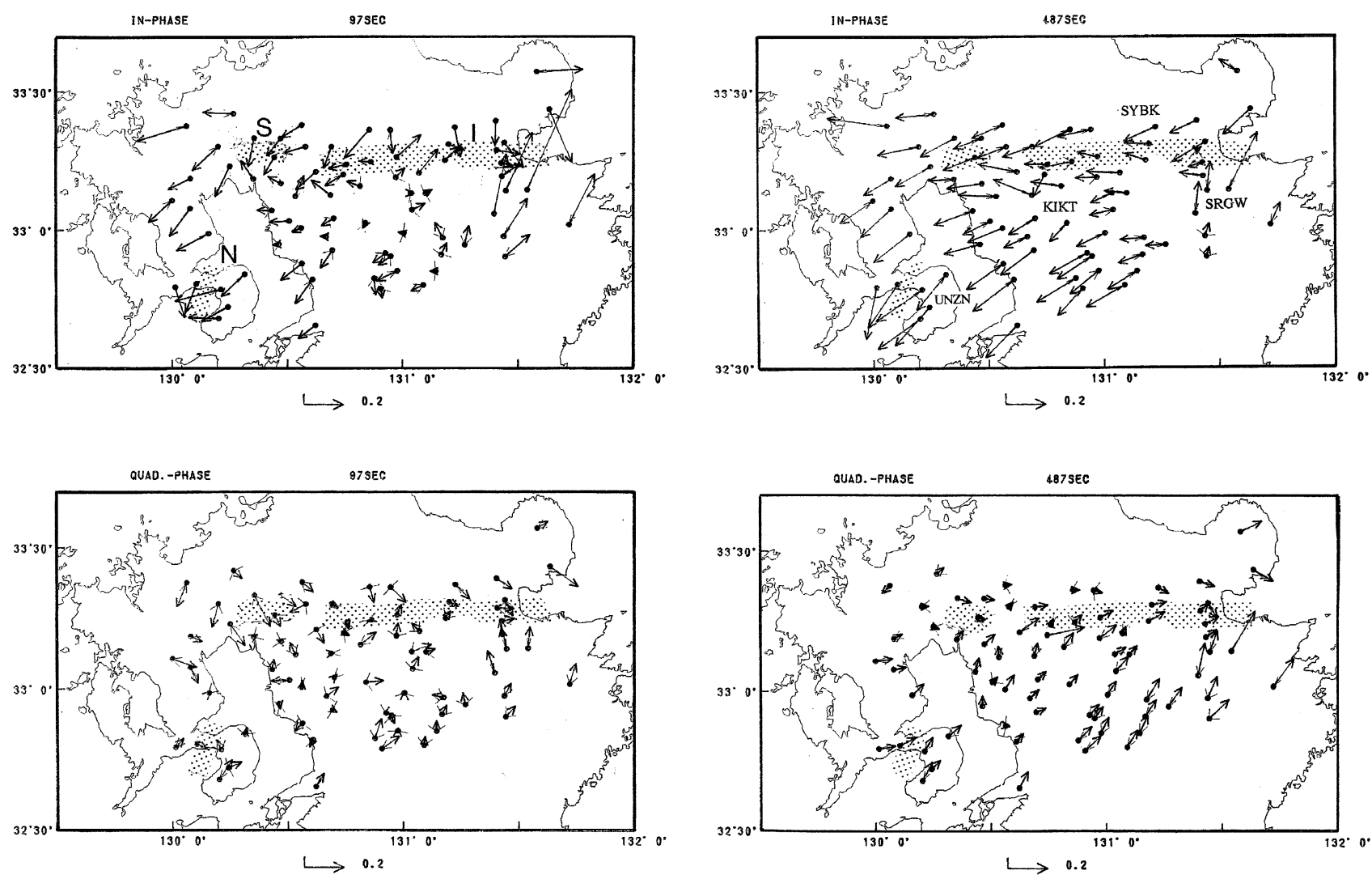

Fig. 2. Induction arrows at 97 and $487 \mathrm{sec}$. Shaded areas I, N and S indicate presumed conductivity anomaly. Plus or minus one standard deviation of azimuthal uncertainty in each arrow is marked by the short lines drawn from the foot of the arrow.
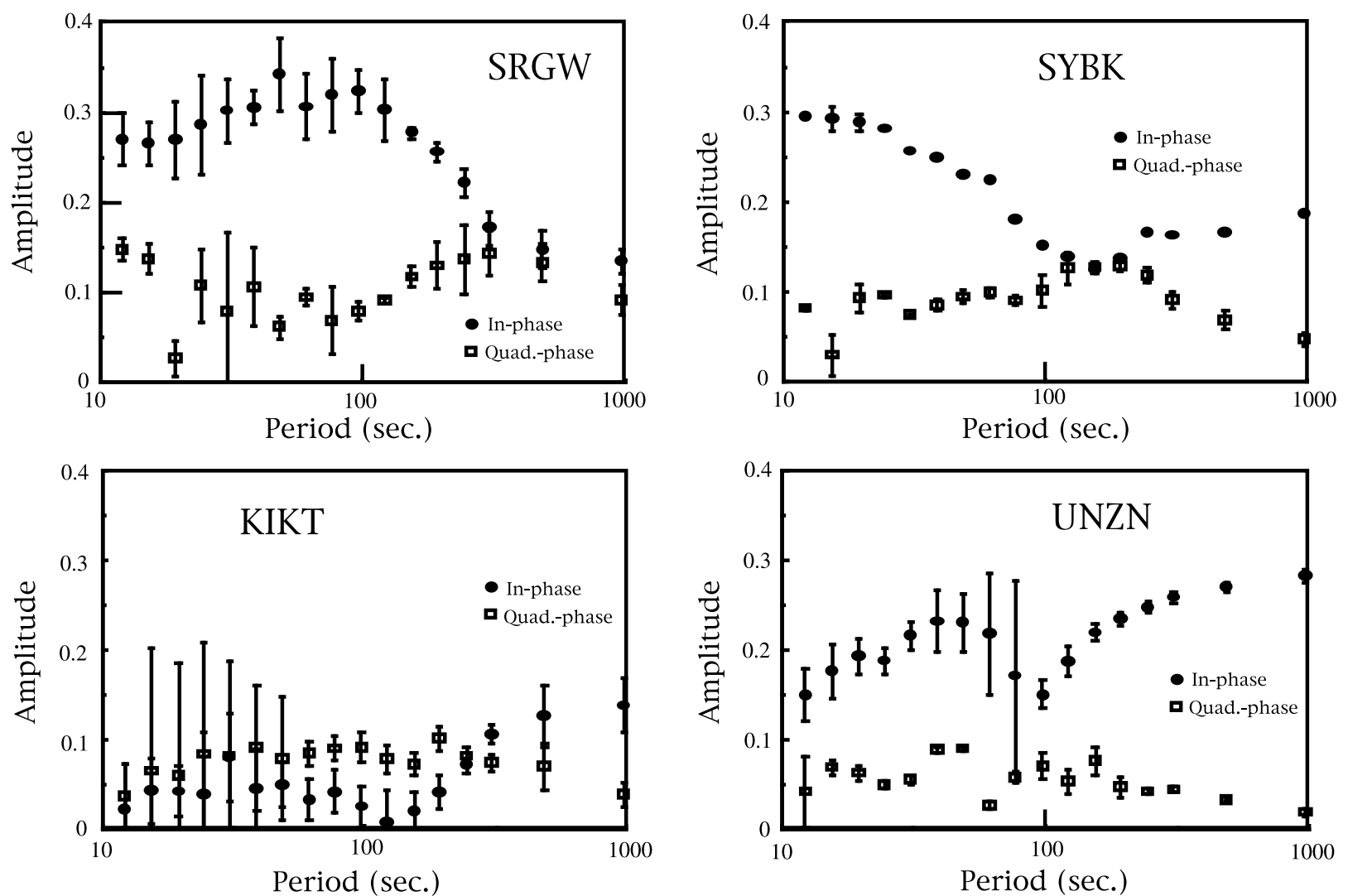

Fig. 3. Amplitude of induction arrows at four sites as a function of the period. Lines indicate \pm 1 S.D. 
Fig. 3 also supports this tendency: The in-phase amplitude decreases gradually with a decreasing of the period and reaches a minimum at about $120 \mathrm{sec}$, as typically seen at UNZN. This is a common response in central Kyushu, except for the eastern part where the in-phase arrows tend to point towards the east (e.g. SRGW in Fig. 2), because the effect of the Seto Inland Sea is rather dominant. The decrease of amplitudes can be explained from the fact that the $z$-component variations of magnetic field decrease rapidly as far from the coastline and with a decreasing period. In contrast, the shorter-period amplitudes less than about 120 $\mathrm{sec}$ are quite local. Thus, we will use the GDS data for periods shorter than about $120 \mathrm{sec}$ in the thin sheet modeling.

\section{Thin Sheet Modeling}

In order to obtain a conductance distribution in the shallow crust, the thin sheet modeling was carried out using these GDS data. We used a model of $94 \times 94$ grids with a grid-node spacing of $5 \mathrm{~km}$, which is adopted on the basis of the mean distance between the adjacent observation sites considering the skin depth of the layer below the thin sheet. A non-uniform thin sheet with thickness $(h 1)$ of 0.7 $\mathrm{km}$ is assumed to be underlain by two layers; the first layer, immediately below the thin sheet, is $50 \mathrm{~km}$ thick with a uniform conductivity of $0.005 \mathrm{~S} / \mathrm{m}$, and the bottom layer is a half-space with a conductivity of $0.01 \mathrm{~S} / \mathrm{m}$. The previous thin sheet model (Shimoizumi et al., 1997) suggests that a conductivity of 0.001 and $0.01 \mathrm{~S} / \mathrm{m}$ is the crust and the upper mantle values, respectively, which best explains the long-period arrows when only the land-sea configuration is considered. The resistive crust is also suggested by the MT results observed in the Aso area (Handa et al., 1992). Although the value of $0.005 \mathrm{~S} / \mathrm{m}$ seems to be large, we must adopt this value to satisfy the thin sheet model condition that the area $(470 \times 470 \mathrm{~km})$ should be large enough compared to the skin depth of the first layer $(78.6 \mathrm{~km}$ for the period of $122 \mathrm{sec}$ ) (Agarwal and Weaver, 1989), because the modeling size of $94 \times 94$ is almost maximum for the computer resources.

We firstly constructed the initial thin sheet model, which is based on the surface geology shown in Fig. 1. In this model, the thin sheet conductance of land is $3.5 \mathrm{~S}$ except for the areas covered with rocks of the Chichibu belt $(0.78$ S) between OKL and BTL in Fig. 5, granite $(0.78 \mathrm{~S})$, and Quaternary sediments (7 S). When the sea is shallower than $700 \mathrm{~m}$, conductance in the surrounding sea with depth $d$ (m) is estimated at $4 d+0.005(700-d)$, where seawater is $4 \mathrm{~S} / \mathrm{m}$ and the layer beneath the sea is assumed to have a conductivity of $0.005 \mathrm{~S} / \mathrm{m}$. Conductance is assumed to be $4 d$ in the sea with a depth of over $700 \mathrm{~m}$, which is an exceptional case in our model.

The in-phase and the quadrature arrows were calculated for the periods of 77, 97 and $122 \mathrm{sec}$ using the thin sheet technique (McKirdy et al., 1985). The thin sheet approximation (Schmucker, 1970) requires that the thickness $(h 1)$ must be less than a third of the skin depth $(\delta 1)$ in the sheet. Since the quantity of $h 1 / \delta 1$ increases with increasing conductance of the sheet, the largest value usually appears in seas. The minimum period satisfying the condition $(h 1 / \delta 1<0.3)$ is $69.8 \mathrm{sec}$ where conductivity of the thin sheet is $4 \mathrm{~S} / \mathrm{m}$ and $h 1$ is $0.7 \mathrm{~km}$. The period is also restricted by the area size or the grid-node spacing, as mentioned previously. In this model, the maximum period is about 122 sec. This is the reason why these periods were selected.

Next, we carried out the inversion adopting a conjugate gradient relaxation method based on the procedure described by Wang and Lilley (1999). The smoothing parameter $(\lambda)$ of $4 \times 10^{-4}$ is adopted, which controls the balance between the data misfit function $L(m)$ and the model characteristic function $R(m)$. That is, an object function $(\Phi)$ of a model $\mathrm{m}$ is defined by $\Phi(m)=L(m)+\lambda R(m)$. These functions for this case are given as follows (Wang and Lilley, 1999):

$$
L(m)=1 / 2\left\{d_{\mathrm{obs}}-g(m)\right\}^{T} C_{d}^{-1}\left\{d_{\mathrm{obs}}-g(m)\right\},
$$

where $C_{d}^{-1}$ is a covariance matrix describing the errors in the observed data and $d_{\mathrm{obs}}$ and $g(m)$ are the observed data and the calculated response, respectively.

$$
R(m)=1 / 2 m^{T} \partial_{x}^{T} \partial_{x} m+1 / 2 m^{T} \partial_{y}^{T} \partial_{y} m
$$

where $\partial_{x}$ and $\partial_{y}$ are operators which take the difference between the model parameters of adjacent cells in the $x$ and $y$ directions, respectively. The parameter $\lambda$ is less effective on our inversion result in the range of 0 to 1 , and the value adopted yields to the minimum misfit that is about 2 percent smaller than the misfit for $\lambda=0$.

The inversion was started at the initial model and we finally adopted the model where the sum of the residual values (misfit) is minimum. The misfit is calculated as the data residual parameter, defined as $\Sigma\left|d_{\text {obs }}-g(m)\right|$ (Wang and Lilley, 1999). The sum is taken over all data that are four components for three periods at all the observation sites. In this process, the conductance values for the surrounding sea regions were kept fixed, but for the shallow seas- that is, the Ariake Sea, the Beppu Bay, and the Tachibana Baychanging conductance values was permitted when the inverted values are larger than those in the initial model.

The sum of the residual values slightly decreased from 47.97 to 37.02 by the inversion. The large misfit, in detail occurs in the $y$-components $(B u$ and $B v)$ : The residues for $B u$ and $B v$ change from 12.45 to 11.37 and from 9.37 to 9.03, respectively, while that for $A u$ successfully decreases from 18.33 to 8.7 . This $y$-component misfit is possibly caused by the land-sea configuration in our model. The thin-sheet modeling method in this study prohibits vertical current leakage, which depresses the transfer functions particularly near coastlines (Kuvshinov et al., 1999). Thus, some misfits are caused by this restriction in the eastern and western areas near the coastline. However, as the large misfits are even found in the central part, the following causes should be considered in this case. As the current flow in the NS direction, which is induced by geomagnetic field variations concentrates in the East China Sea, the current density is relatively low in central Kyushu, while the EW current is not so strongly, governed by the land-sea configuration. Thus, the conductance perturbations on land can cause the relatively small change of the $B u$ value in the inversion process. This is clearly shown in Fig. 4: the sensitivity of $B u$ to normalized conductance (McKirdy et al., 1985) perturbations in the cell is about a third of others. For these reasons, 


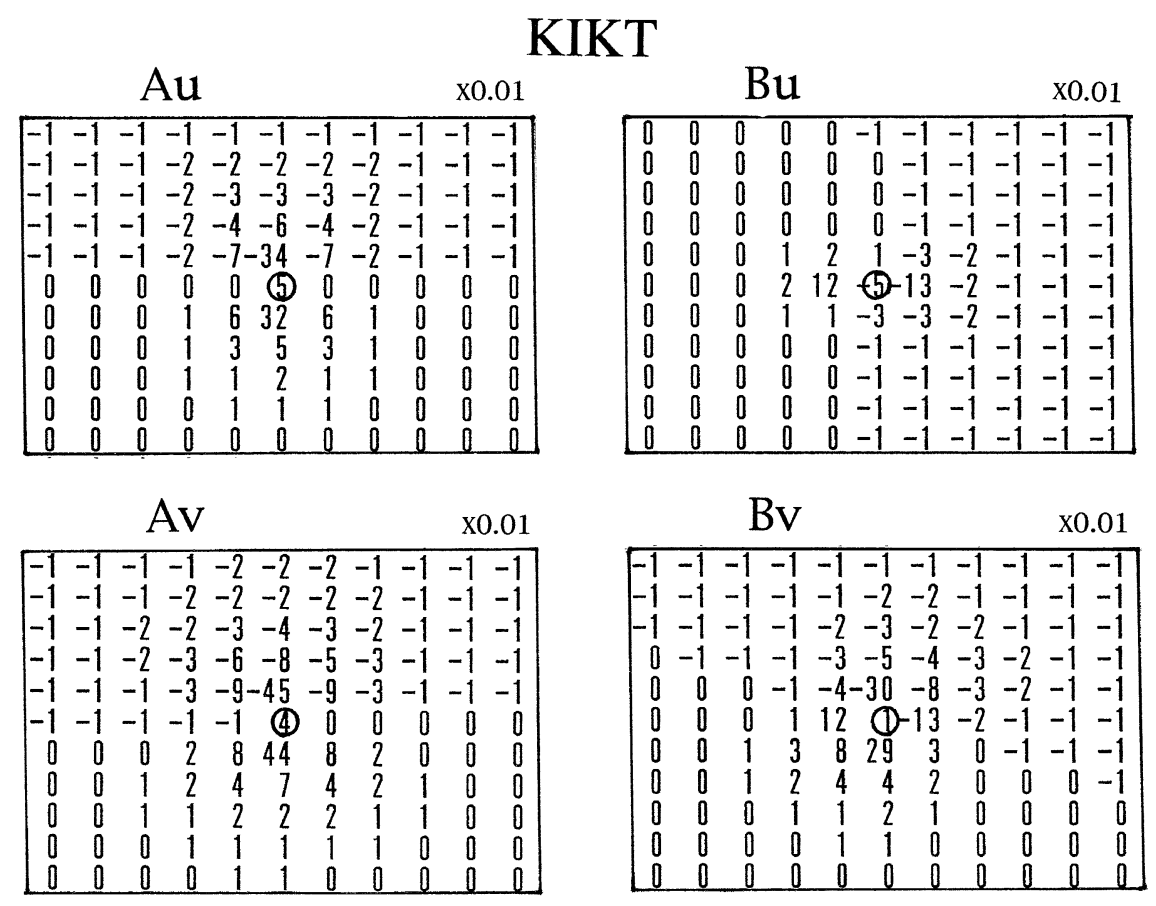

Fig. 4. The sensitivity to conductance perturbations in the cell of $A u, v$ and $B u, v$ data at the central cell (KIKT) marked by a circle. Sensitivity maps are shown for the period of $97 \mathrm{sec}$.
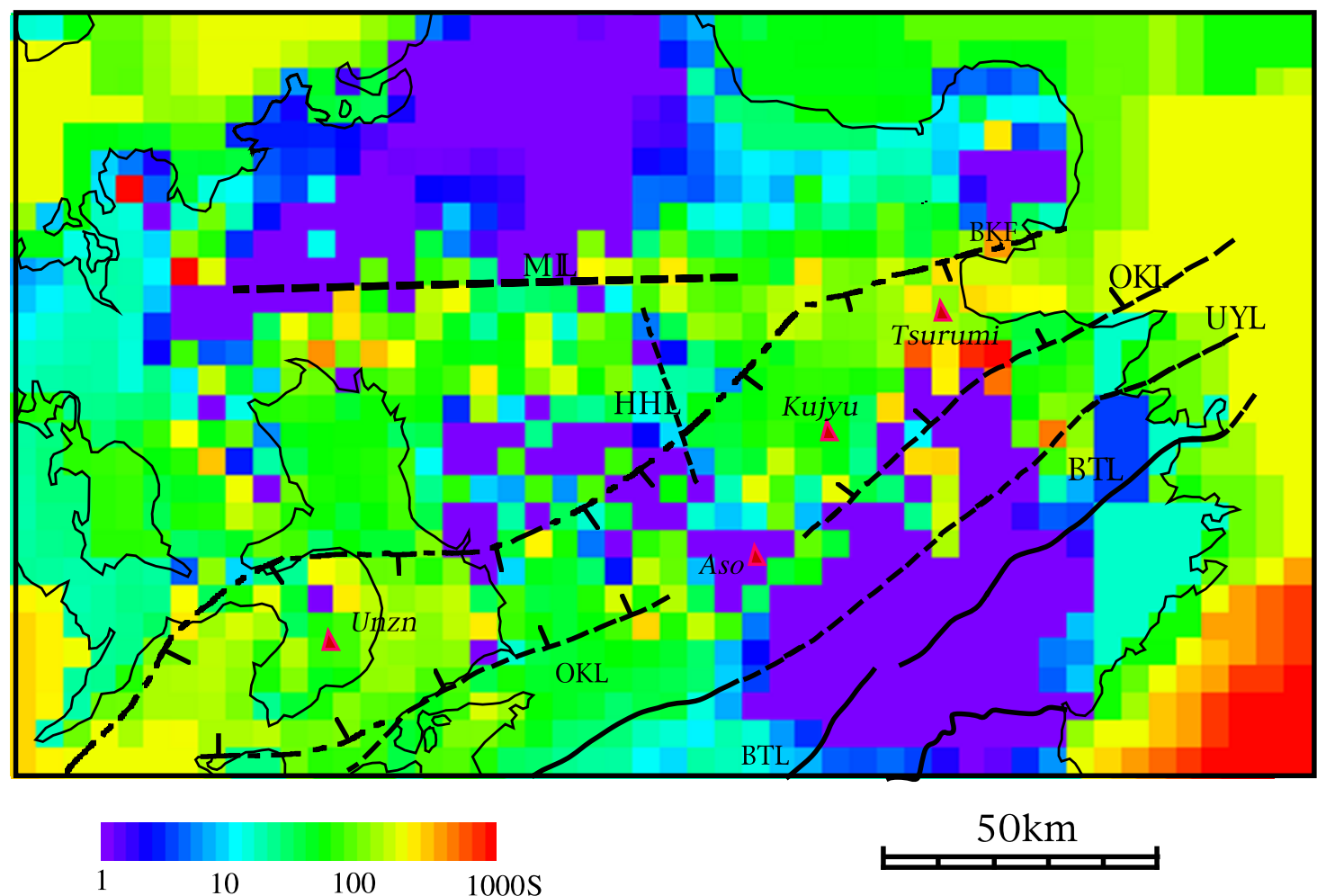

Fig. 5. The final thin sheet model. Triangles show active volcanoes. BKF: Beppu-Kita fault, BTL: Butsuzo tectonic line, HHL: Hita-Hakuso tectonic line, MIL: Matsuyama-Imari tectonic line, OKL: Oita-Kumamoto tectonic line, UYL: Usuki-Yatsushiro tectonic line.

the reduction of the misfit in the $y$-component of the transfer function is difficult only through this inversion process.

Moreover, another limitation of this model is seen in Fig. 4: an 'effective sensitivity range' that is the distance in which a sensitivity value decays to half of its maximum value (Wang and Lilley, 1999) is a radius of one cell. This mean that only the conductance perturbation at the adjacent cells can effectively change the transfer functions and the flexibility of modeling is poor. Grid-spacing shorter than $5 \mathrm{~km}$ should be assigned to avoid this problem, but that is 


\section{Initial model}
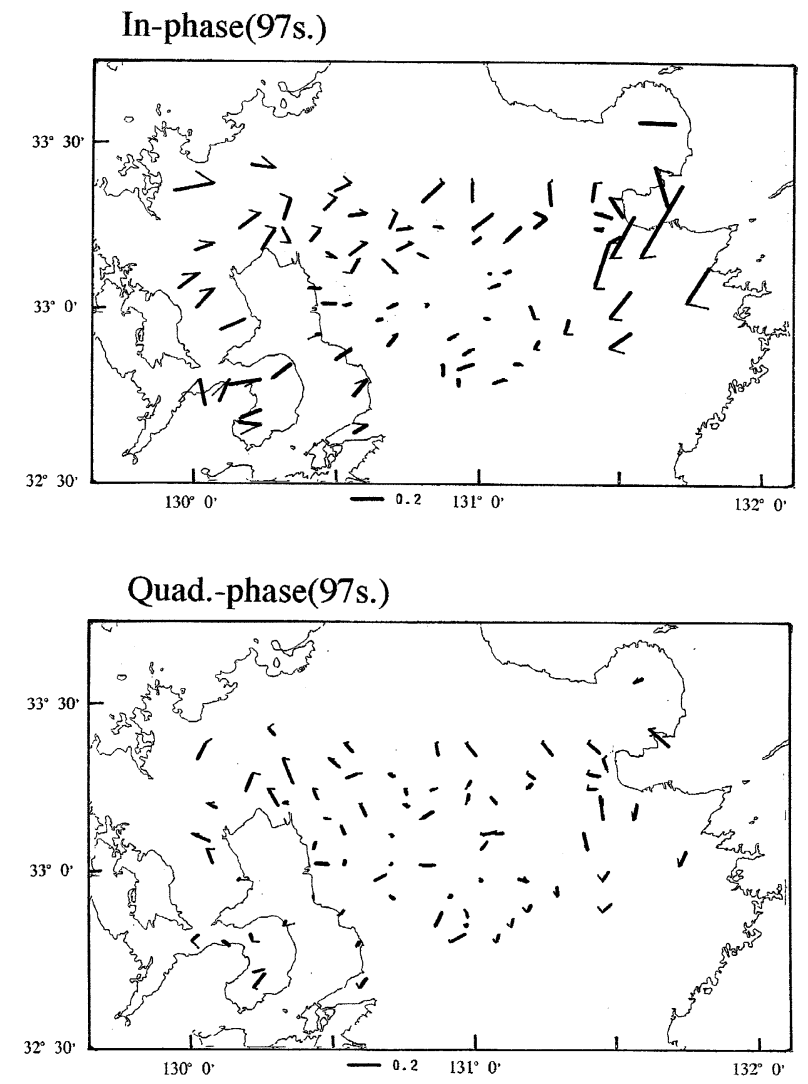

Final model
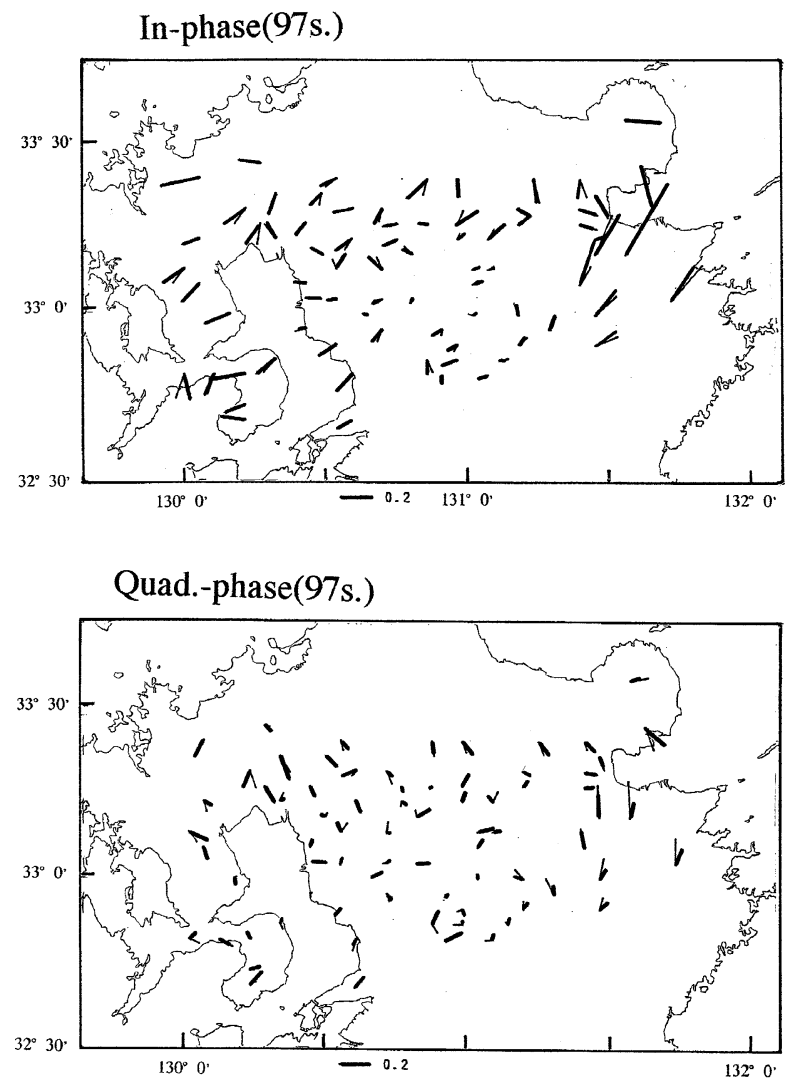

Fig. 6. Response of in-phase and quadrature induction arrows for $97 \mathrm{sec}$., which are calculated for the initial and the final models. Observed arrows are indicated by thick lines.

difficult because of the limitation of the thin sheet condition, as mentioned before.

In order to overcome these problems, the trial and error modeling technique was applied after inverting the initial model, and then the inversion was made again. By this procedure, the total residue finally decreased to 23.7. The average residue for a component at a site is 0.026 . This inverted conductance distribution (the final model) is shown in Fig. 5. The in-phase and the quadrature arrows calculated for the initial and the final models are shown in Fig. 6 along with those observed for the period of $97 \mathrm{sec}$. The arrows for 77 and $122 \mathrm{sec}$ are not shown here because they are similar to those in Fig. 6. Comparing these figures in Fig. 6, it is found that the misfit improves for the in-phase arrows, while there are still some misfits of the quadrature-phase arrow mainly due to the relatively large estimation errors caused by cultural noises.

\section{Discussion}

The conductive areas with enhanced conductance of more than $10 \mathrm{~S}$ after the inversion process are illustrated in Fig. 7 for convenience of the following discussion. We will discuss three relatively broad areas marked by B, S and $\mathrm{U}$, which include the high-conductivity areas expected from the induction arrow data in Fig. 2.

\subsection{High-conductive alluvial plain}

The main part of the conductive area ' $S$ ' covers the Saga-Chikugo plain. This high conductivity is probably due to alluvium with a thickness of about $200 \mathrm{~m}$; in the Saga-Chikugo plain, unconsolidated sediments including the 'Ariake clay' are underlain by Palaeogene sediments. The Ariake clay, which lies near the ground surface with a thickness of several meters, is quite high-conductive and the surface layer including Ariake clay has a resistivity in the range from 5 to $25 \Omega-\mathrm{m}$. This implies that conductors much thinner than the skin depth can intensely affect the induction arrows by concentrating the induced current into such areas, as Nishida (1976) pointed out in the GDS study of southern Hokkaido.

\subsection{Conductivity structures in the BSG}

The area ' $\mathrm{B}$ ' is the most conductive region. The conductive belt ' $M$ ' from Beppu Bay to the west along MIL and BKF (Fig. 2) is suggested from the observed induction arrows. The final model indicates that the high-conductivity zones are found in this area along almost all the tectonic lines; MIL, BKF, OKL and possibly UYL. These tectonic lines are not only traced by the high-conductivity belt but also the border of a high-conductive triangular region of the Hohi volcanic zone.

The Hohi volcanic zone is characterized by a 'boxshaped negative anomaly' (Kamata, 1989) as seen in the contour map of the Bouguer anomaly in Fig. 7. The gravimetric analysis and drill hole data indicate that the preTertiary basement is a half-graben structure filled with volcanic formations: the cross-section along the line AB (Kamata, 1993) is shown in Fig. 8, in which a maximum depth 


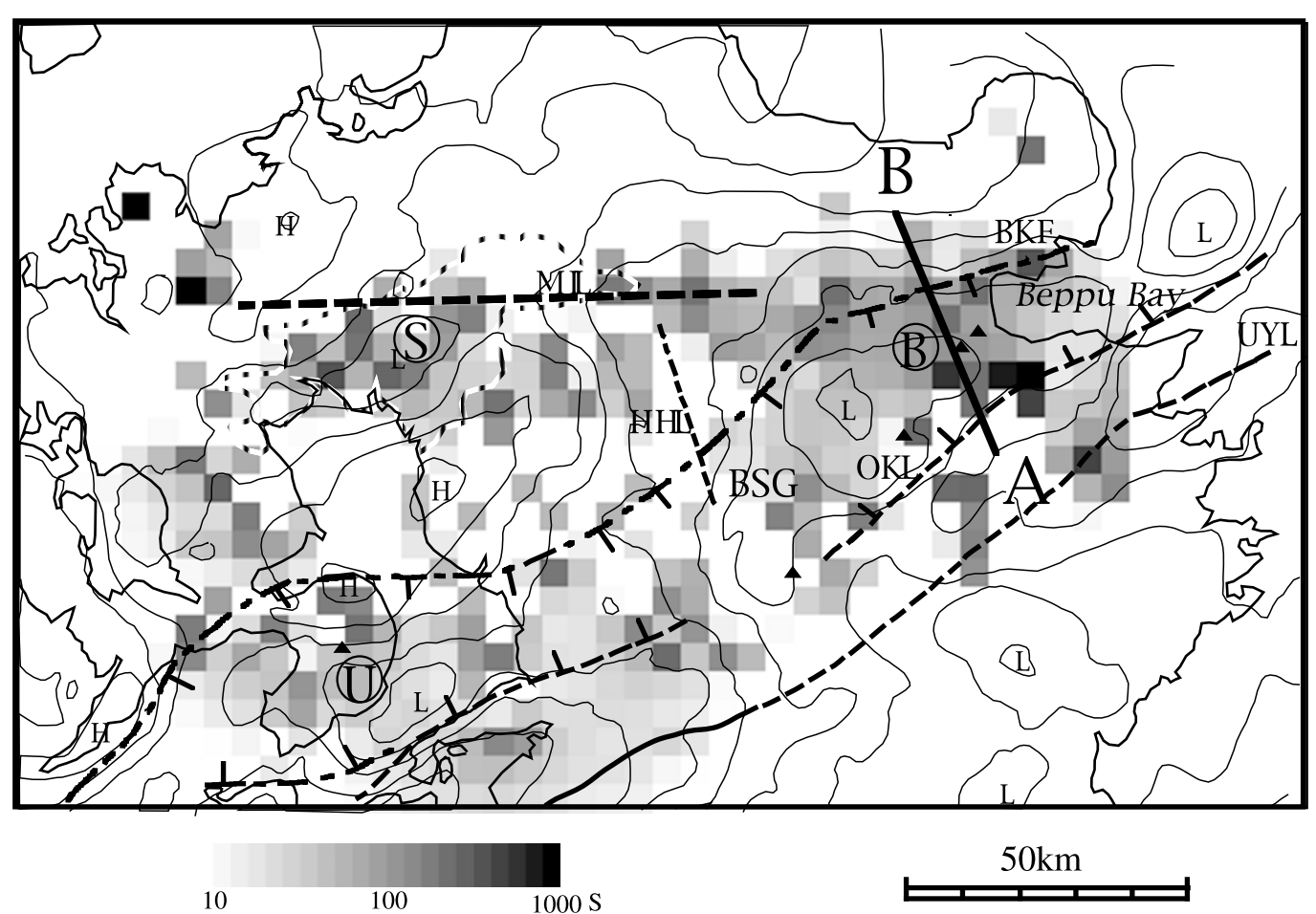

Fig. 7. Tectonic interpretation of the electrical conductivity model in central Kyushu. The enhanced conductance values compared with the initial model are indicated. The region surrounded by a broken line indicates Quaternary sediments of the Saga-Chikugo plain. The Bouguer gravity anomaly is shown by thin lines with an interval of 20 mgals, which is compiled from Geological Survey of Japan (2002a and b). The shallow structure of the graben is shown along line AB in Fig. 8. Triangles indicate active volcanoes. BKF: Beppu-Kita fault, HHL: Hita-Hakuso tectonic line, MIL: Matsuyama-Imari tectonic line, OKL: Oita-Kumamoto tectonic line, UYL: Usuki-Yatsushiro tectonic line.

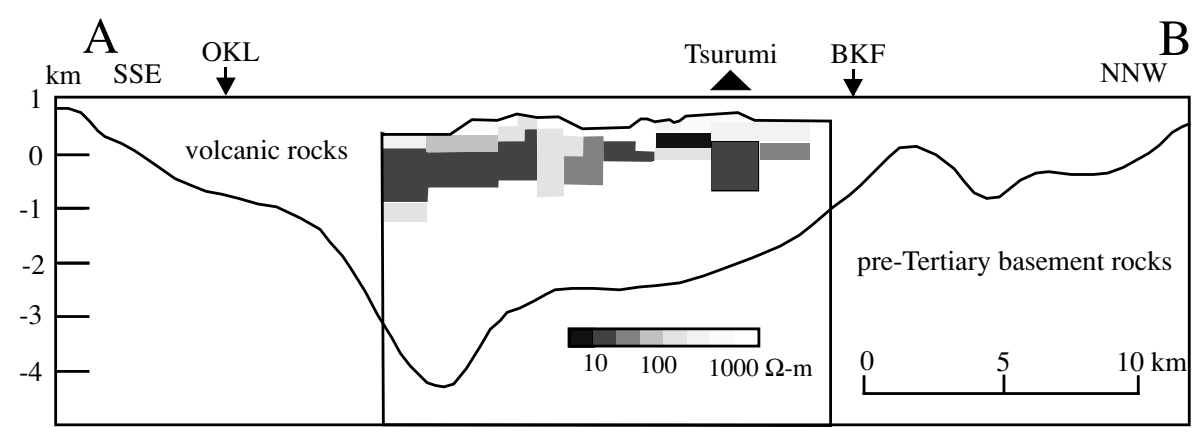

Fig. 8. The graben structure estimated from the gravimetric data and the 2-D conductivity model along AB, compiled from Kamata (1993) and NEDO (1989), respectively.

of $5 \mathrm{~km}$ appears at the north of OKL and the basement rises gradually in its northern part. The 2-D electrical conductivity structure (NEDO, 1989) is also shown in this figure, which is obtained by the long-period MT and the CSAMT data that is along the line at about $1 \mathrm{~km}$ east and roughly parallel to the line AB. This model implies that the shallow part of volcanic formations within the graben is highly conductive and underlain by a resistive layer of $1000 \mathrm{ohm}-\mathrm{m}$, and the basement is not clarified in contrast to the structure estimated from the gravimetric data.

The correlation is good between the shallow part of the 2-D conductivity structure and our final model: For example, a high-conductive zone across the line $\mathrm{AB}$ at the immediately north of OKL is seen in the thin sheet model, which possibly corresponds to the most conductive layer of $10 \mathrm{ohm}-\mathrm{m}$ at the same position in the 2-D model. This implies that the thin sheet model reveals conductive layers shallower than about $1 \mathrm{~km}$ depth at least around the line $\mathrm{AB}$ and possibly in all the $\mathrm{B}$ area.

The BSG occupies the eastern region of the Hohi volcanic zone. This is a tectonically active zone: The surface geology indicates that many normal-type faults with the east-west strike are well developed and form the Beppu graben. In the Beppu bay where conductivity is high, multichannel seismic reflection and gravity surveys delineated several faults in the sedimentary layer covering the depressed basement that undulates within a few thousand meters (Yusa et al., 1992). Also, geothermal activity is high, as is evident from hot water springs and fumaroles in the $\mathrm{B}$ area. These imply a close relation between the high- 
conductivity structure including the zone along the tectonic lines and geothermal system, because high-conductivity in the shallow crust is frequently caused by geothermal activity.

In a western area of central Kyushu, the narrow highconductivity zone is expected from the anti-parallelism of in-phase arrows in the root of the Shimabara peninsula $(\mathrm{N}$ in Fig. 2). The inverted result, however, indicates that the conductive region is spread out widely; the BSG and the zone between the OKL and UYL. In the peninsula, the Unzen graben runs across the central part in the EW direction and the Unzen active volcano stands within the graben. The shallow conductive layer that can explain high-conductivity of the thin sheet model is also found in this area: The MT survey in the peninsula indicates that the extremely conductive layer of a few ohm-m at a depth of about 1 to $2 \mathrm{~km}$ lies between the highly resistive surface layer and a layer of about 100 ohm-m (Yamamoto et al., 1996).

The conductive zone of the western BSG is bounded on the east by the Aso area which is resistive, as seen in Fig. 7, and the BSG seems to be discontinuous in the shallow electrical structure. In this high-resistive area, no clear fault system of the graben is found by the surface geology. Although the negative gravity anomaly that is the most important evidence of the BSG is found in this area, it does not indicate the graben but the caldera structure that is filled with lighter materials ejected by eruptions of the Aso volcano. Thus, the central portion is tectonically different from the other areas and the BSG is possibly separated into three parts in the shallow electrical structure; the high-conductive eastern and western zones and the resistive central area.

\section{Conclusion}

The conductivity structure in the shallow crust of central Kyushu is clarified by the thin sheet inversion method using the GDS data set for the periods of 77, 97 and $122 \mathrm{sec}$. In the modeling process, the fitness of the $y$-component in the in-phase transfer functions is not easily improved only by the inversion method, because of the land-sea configuration in this model: as current flow in the NS direction concentrates in the East China Sea, the sensibility of the $y$ component transfer functions to conductance perturbations at a cell on land is about a third of the others. This can be overcome by partly applying the trial and error method and the fit of the model finally obtained is sufficient.

The inverted model reveals that the high-conductive areas distributed widely in central Kyushu; the Chikugo-Saga alluvial plain and the eastern and the western areas including the BSG. The MT results imply that the conductivity map obtained represents the distribution of the conductive layers shallower than about $1 \mathrm{~km}$. The eastern and the western parts of the BSG, which are the tectonically active zones in Beppu and the Shimabara peninsula, are intensely conductive. These conductive areas are not localized only in the BSG but also found in the zone between two tectonic lines of OKL and UYL in the Shimabara area and in the Hohi volcanic zone. In the Beppu area, the highconductivity zones are found along the tectonic lines bounding the BSG. In contrast, the central part of the BSG is resistive, in which no clear graben structure is found by the surface geology. Thus, the BSG is not revealed as a continuous high-conductive belt and it is separated into three parts. That is the eastern and the western high-conductive zones and the resistive central area in the electrical conductivity model.

Acknowledgments. I would like to express my thanks to Dr. H. Toh for providing the computer program of the thin sheet calculation. Constructive reviews by Dr. S. G. Gokarn and the anonymous reviewers significantly improved the manuscript.

\section{References}

Agarwal, A. K. and J. T. Weaver, Regional electromagnetic induction around the Indian peninsula and Sri Lanka; a three dimensional numerical study using the thin sheet approximation, Phys. Earth Planet. Inter., 54, 320-331, 1989.

Editorial Committee of Kyushu, Part 9 of Regional Geology of Japan, Regional Geology of Japan Part 9 Kyushu, 371 pp., Kyoritsu Shuppan, Tokyo, 1992.

Egbert, E. D. and J. R. Booker, Robust estimation of geomagnetic transfer functions, Geophy. J. R. Astr. Soc., 87, 173-194, 1986.

Eguchi, T. and S. Uyeda, Seismotectonics of the Okinawa Trough and Ryukyu Arc, Mem. Geol. Soc. China, 5, 189-210, 1983.

Geological Survey of Japan, Gravity map of Fukuoka district (Bouguer anomaly), Geol. Surv. Japan, 2002a.

Geological Survey of Japan, Gravity map of Ooita district (Bouguer anomaly), Geol. Surv. Japan, 2002b.

Handa, S., Y. Tanaka, and A. Suzuki, The electrical high conductivity layer beneath the northern Okinawa Trough, inferred from geomagnetic depth sounding in Northern and Central Kyushu, Japan, J. Geomag. Geoelectr., 44, 505-520, 1992.

Kamata, H., Volcanic and structural history of the Hohi volcanic zone, central Kyushu, Japan, Bull. Volcanol., 51, 315-332, 1989.

Kamata, H., Subsurface geologic structure and its genesis of Beppu Bay and adjacent area in central Kyushu, Japan, J. Geol. Soc. Japan, 99, 3946, 1993 (in Japanese with English abstract).

Kuvshinov, A. V., D. B. Avdeev, and O. V. Pankratov, Global induction by Sq and Dst sources in the presence of oceans: bimodal solutions for nonuniform spherical surface shells above radially symmetric earth models in comparison to observations, Geophys. J. Int., 137, 630-650, 1999.

Matsumoto, Y., Some problems on the volcanic activities and depression structures in Kyushu, Japan, Mem. Geol. Soc. Japan, 16, 127-139, 1979 (in Japanese).

McKirdy, D. McA., J. T. Weaver, and T. W. Dawson, Induction in a thin sheet of variable conductance at the surface of a stratified earth-II. Three-dimensional theory, Geophy. J. R. Astr. Soc., 80, 177-194, 1985.

Nakada, T. and H. Kamata, Temporal change in chemistry of magma source under Central Kyushu, Southwest Japan: progressive contamination of mantle wedge, Bull. Volcanol., 53, 195-206, 1991.

NEDO, Report of the resistively survey (MT and CSAMT) in the TsurumiDake area, NEDO, 1989 (in Japanese).

Nishida, Y., Conductivity anomalies in the southern half of Hokkaido, Japan, J. Geomag. Geoelectr., 28, 375-394, 1976.

Parkinson, W. D., The influence of continents and oceans on geomagnetic variation, Geophys. J., 6, 441-449, 1962.

Schmucker, U., Anomalies of geomagnetic variations in the southwestern United States, Bull. Scripps Inst., 13, Univ. of Calif. Press, 1970.

Shimoizumi, M., T. Mogi, M. Nakada, T. Yukutake, S. Handa, Y. Tanaka, and H. Utada, Electrical conductivity anomalies beneath the western sea of Kyushu, Japan, Geophys. Res. Lett., 24, 1551-1554, 1997.

Wang, L. J. and F. E. M. Lilley, Inversion of magnetometer array data by thin-sheet modelling, Geophys. J. Int., 137, 128-138, 1999.

Yamamoto, T., T. Kagiyama, and H. Utada, Resistivity structure by ULFMT around Unzen Volcano, SW Japan, 13th Workshop on Electromagn. Ind. In the Earth, 1996.

Yusa, Y., K. Takemura, K. Kitaoka, K. Kamiyama, S. Horie, I. Nakagawa, Y. Kobayashi, A. Kubotera, Y. Sudo, T Ikawa, and M. Asada, Subsurface structure of Beppu Bay (Kyushu, Japan) by seismic reflection and gravity survey, Zisin, 45, 199-212, 1992 (in Japanese with English abstract).

S. Handa (e-mail: handas@cc.saga-u.ac.jp) 